no la tiene al afirmar (p. 109) que el libro de Güiraldes "valdrá cuanto se quiera, pero no tiene, precisamente por ser gauchesco, significación representativa". La significación de esta novela, tal como yo la entiendo, está representada por la figura del muchacho que, como su patria, al llegar a la mayoría de edad se independiza, aunque no sin dolor, del inútil mito del gaucho ${ }^{1 *}$.

J. M. AguirRe

University College, Cardiff.

\title{
UN POEMA DE CÉSAR VALLEJO
}

La crítica sobre Vallejo nunca ha sido tan fecunda como en estos últimos años. Los importantes trabajos de José María Valverde en España, de Luis Monguió en los Estados Unidos (ambos de 1952), de Juan Larrea (1957) y de Saúl Yurkievich (1958) en la Argentina, de Xavier Abril en el Uruguay (1958), que han venido a sumarse a los muchos prólogos, artículos y ensayos precedentes, representan un notable paso adelante en el estudio del gran poeta peruano'.

Con todo, hasta hoy la crítica se ha dedicado más al estudio de la poética, la temática, las premisas socio-culturales, las condiciones psicológicas, los acontecimientos biográficos, que al análisis propiamente semántico y estilístico (textual) de la obra vallejiana.

Era lógico - y necesario - que asi fuera, porque sin un trabajo'que arroje luz sobre el mundo interno y externo del poeta, sería casi imposible emprender, con alguna probabilidad de acierto, la crítica textual de un autor tan difícil y complejo como Vallejo. El mismo Larrea, que por su condición de poeta y su entrañable amistad con el peruano puede llegar a escudriñar mejor que nadie sus valores recónditos, reconoce que la obra de Vallejo es sumamente difícil y "voluntariamente consagrada al absurdo"2. Análogamente, Xavier Abril, que se halla en las mismas condiciones que Larrea, declara que "la simple crítica literaria no ha resuelto todavía el problema que plantea el pensamiento hermético del poeta"'s.

La filología debe, pues, gratitud al grupo de estudiosos que ha sabido roturar el complejo terreno del mundo espiritual vallejiano y del humus histórico-cultural-sociológico en que surgió. Pero ello no quiere decir que la obra de estos estudiosos deba considerarse concluida, sino sólo que

${ }^{14}$ Cumplo con gusto el deber de agradecer a mis colegas, el catedrático señor Stephen Reckert y la señora Lorna J. Ciose, sus generosas y valiosísimas sugestiones, que tanto me han ayudado para clarificar y precisar algunas de las ideas expuestas cn este artículo.

${ }^{1}$ El presente trabajo fue presentado como comunicación al Symposium de estudios vallejianos organizado por el Instituto del Nuevo Mundo de la Universidad de Córdoba (Argentina) en agosto de 1958. Como hasta la fecha (junio de 1969) no se han impreso las actas del Symposium, he resuelto publicarlo por separado (con algunas modificaciones que debo a amable sugerencia del Prof., Oreste Macrì, de la Universidad de Florencia).

2 Juan Larrea, césar Vallejo, o Hispanoamérica en la cruz de su razón, Córdoba, Argentina, 1957, p. 14 .

Xavier ABril, Vallejo, Buenos Aires, 1958, p. 95. 
ahora está madura la situación para emprender estudios sistemáticos de carácter más estrictamente semántico y estilístico ${ }^{ \pm}$. $\mathrm{Y}$ no es que los dos tipos de estudio deban delimitar su ámbito mediante un corte neto. Al contrario, asi como el crítico de la poética, la temática y la problemática de Vallejo no puede trabajar fuera del texto concreto en que se ha materializado el mundo interior del poeta, del mismo modo el crítico de la forma no puede prescindir de aquel mundo interior y de la cosmovisión correspondiente. Si lo hiciera, tendría razón Xavier Abril cuando afirma (generalizando algo más de la cuenta) que no cree "que la estilística alcance a descifrar la incógnita [de la poesía] más allá de los accidentes gramaticales" (op. cit., p. 100).

Mucho tiempo les ha de llevar a los críticos desentrañar los complejos valores semánticos y estilísticos, muy a menudo subterráneos e inasibles, de la obra de Vallejo, sobre todo del Vallejo más maduro de Trilce y de Poemas humanos. Considero que en esta difícil tarea conviene, tal vez, empezar por orden cronológico, no tanto por ser más transparentes los primeros poemas, como por contener, in nuce, aquellos elementos estilísticos que irán desarrollándose y complicándose en las etapas sucesivas.

Por esta razón metodológica analizo aquí un poema del primer libro de Vallejo, Los heraldos negros, el cual, contra lo que suele afirmarse, contiene valores poéticos de gran envergadura. Se trata de "Capitulación", poema de amor.

Varios son los objetos del amor en Vallejo, poeta cuya ternura es "el secreto de su poderosa, invasora, inalienable originalidad"s: la mujer, Dios, el hogar (con sus familiares), la amistad, la humanidad, España... ${ }^{6}$ Claro está que este orden no es axiológico, sino meramente cronológico: es el orden en que esos objetos aparecen por primera vez en la obra. He elegido el tópico del amor a la mujer, por ser el primero que se muestra ante los ojos del lector al entrar en Los heraldos negros.

Aunque en Vallejo tal tipo de amor presenta otras facetas -amor sentido como pecado (cf. "Amor prohibido" en Los heraldos negros), amor como mito de pureza (cf. "Para el alma imposible de mi amada" o bien "Deshora", ibid.), amor sensual (cf. "Amor", ibid.)-, he escogido el poema "Capitulación" por aparecer en él el amor que llamamos normal, y por tratarse de una de las producciones más hermosas dentro de este capítulo. He aquí el texto:

Anoche, unos abriles grana capitularon ante mis mayos desarmados de juventud; los marfiles histéricos de sus besos me hallaron muerto; y en un suspiro de amor los enjaulé.

Espiga extraña, dócil. Sus ojos me asediaron una tarde amaranto que dije un canto a sus cantos; $y$ anoche, en medio de los brindis, me hablaron

4 Tres años después de haber escrito el presente trabajo, publiqué mi libro stile $e$ poesia in César Vallejo (Padova, 1960), en el cual he intentado justamente un análisis semántico y estilístico del Himno a los voluntarios de la República.

- Dámaso Alonso, Poetas españoles contemporáneos, Madrid, $195^{2}$, p. $3{ }^{5}$.

- Sobre el papel del amor que "invade, en la poesía de Vallejo, todo lo que canta o invoca", cf. Xavifr Abril, op. cit., pp. 79-80. 
las dos lenguas de sus senos abrasadas de sed.

Pobre trigueña aquélla; pobres sus armas; pobres

sus velas cremas que iban al tope en las salobres espumas de un marmuerto. Vencedora y vencida, se quedó pensativa, ojerosa y granate.

Yo me partí de aurora. Y desde aquel combate, de noche entran dos sierpes esclavas a mi vida.

La primera estrofa presenta una serie de problemas semánticos. ¿Qué son los mayo? ¿Qué significa mayos desarmados de juventud? ¿Qué valor tiene aquí marfiles histéricos? ¿Y muerto? ¿Y enjaulé?

Los mayos, en oposición a los abriles (años juveniles de la mujer que se le ha entregado) son los años del poeta, que se siente algo más maduro que ella (aunque debía ser muy joven él también: recuérdese que nació en 1892 y que la fecha de publicación de Los heraldos negros es 1918). Desarmados representa una concesiva y corresponde semánticamente a inermes (también etimológicamente equivalente): 'ante mis mayos de juventud, desarmados' = 'ante mis años juveniles, aunque inermes (sin experiencia)'. Tal interpretación es legitimada también por la presencia de una pausa antes y después de desarmados (se trata de un alejandrino trimembre: "ante mis mayos / desarmados / de juventud"). Los mayos desarmados se oponen, pues, a los abriles grana. Son las dos imágenes nucleares. Los abriles van calificados cromáticamente; los mayos, psicológicamente. Téngase en cuenta, además, que en los abriles grana se insinúa ya la imagen de las puntas de los senos, rojas, encendidas, erguidas, que encontraremos en seguida y que constituye el leitmotiv del poema.

En "los marfiles histéricos de sus besos" tenemos, seguramente, una inversión de la imagen: 'sus besos a través de los marfiles (los dientes) histéricos (temblorosos, sacudidos por la emoción erótica)'. Claro que nuestra interpretación (como toda interpretación que quiera ser objetiva y comunicable) representa una racionalización crítica para facilitar la inteligencia del pasaje. En términos poéticos no son lo mismo, naturalmente, 'los marfiles de sus besos' y 'sus besos a través de los marfiles'.

Muerto corresponde a inerte, es decir, aniquilado emocionalmente (antes de ser asaltado) por el empuje vital de esa joven que "capitula" ante él. Este valor de inerte confirma la anterior interpretación de desarmado (inerme) y representa su natural conclusión: inerme $\rightarrow$ inerte.

Los enjaulé corresponde a 'los encerré': 'y, suspirando de amor, encerré en mi boca (y en mis dientes), mediante el beso, sus dientes de marfil (como en una jaula)'.

Desde el punto de vista estilístico, es notable la eficacia de la imagen cromática grana, aplicada predicativamente a una noción temporal (abriles) que a su vez representa, delicadísimamente, la imagen concreta de la joven. Con la adjetivación cromática, y, más aún, con el procedimiento de hacer metáfora de una metáfora, el poeta logra convertir el lugar común (abriles $=a \tilde{n} o s$ ) en imagen poética. De tal manera, los abriles no son ya los años, sino toda una mujer. He aquí las distintas etapas metafóricas de las que es portadora esta palabra: abriles $\rightarrow$ años $\rightarrow$ persona que lleva los años $\rightarrow$ mujer.

Es notable, además, la fuerza y delicadeza (a la vez) de ese color grana 
cuya vivacidad sugiere la juventud, el sabor, la fresca sensualidad de la mujer. $\mathrm{Y}$ en la oposición abriles grana / capitularon asoma en seguida (incluso por el valor casi "estratégico" del verbo capitular) el contraste entre la fuerza de resistencia y la fuerza de entrega de la joven; y la discreta complacencia del poeta ante la capitulación... El epíteto desarmados se sitúa en el mismo plano "bélico", y pertenece al mismo ambiente lingüístico y psicológico que capitularon. Ella capituló, pero el desarmado es él: frente a la juventud, a la fuerza amorosa de la que ella sigue armada, él se siente inerme, o, como lo dirá en seguida, muerto.

El tercer verso se abre con una imagen (marfiles) que también se salva del lugar común por el empleo sustantivo de la metáfora (el poeta no dice dientes de marfil; dice los marfiles); pero decae en seguida por la presencia de histéricos, término técnico, clínico, antipoético, de los tantos que pululan en Vallejo y que, a menudo, no son más que lastre ${ }^{7}$. No es que el término nos resulte duro y desagradable en virtud del ambiente extrapoético que sugiere, sino que no armoniza ni con la "capitulación" precedente ni con el retrato de la mujer tal como se dibuja al comienzo de la estrofa siguiente ("Espiga extraña, dócil").

En el cuarto verso, tras la fuerte pausa que sigue a muerto, el dístico se concluye rápido, felino, con una imagen enérgica y eficaz (los enjaulé): aunque desarmado y muerto, inerme e inerte, el poeta reacciona de pronto y retoma -en el certamen erótico- el papel activo que le corresponde.

Espiga extraña, dócil. Sus ojos me asediaron una tarde amaranto que dije un canto a sus cantos; y anoche, en medio de los brindis, me hablaron las dos lenguas de sus senos abrasadas de sed.

A esta altura, después de la reacción apuntada, la contraparte del papel varonil está representada por la docilidad femenina de la mujer a la que el poeta califica de espiga extraña. Esta metáfora engloba la idea de docilidad (la espiga se deja acariciar fácilmente jaunque en un solo sentido!) y la de fecundidad, elemento siempre presente, de alguna manera, en el amor (el poeta no ha probado todavía los sinsabores y los traumatismos que lo llevarán más tarde a rechazar la idea de la fecundidad, de los hijos). Pero hay otra sugerencia aún: el color de la espiga, imagen que volveremos a encontrar al comienzo de la tercera estrofa (trigueña).

Acabamos de detenernos en la docilidad y he aquí, de nuevo, una imagen de tipo activo, casi agresivo: "Sus ojos me asediaron". Hay una alternancia dialéctica de imágenes activas y pasivas, que marcan el desarrollo de esta historia de amor: capitularon / desarmados / enjaulé / dócil / asediaron. Es esta tensión de oposiciones la que mantiene en equilibrio dinámico la primera parte del poema ${ }^{8}$. En asediaron se sugiere,

"Sobre este problema, en general, cf. SAúl Yurkievich, Valoración de Vallejo, Resistencia, Argentina, 1958, p. 39 .

${ }^{8}$ Sobre el juego dinámico de las oposiciones en Vallejo, con otros valores, cf. J. LARREA, op. cit., p. 28. 
sintéticamente, no sólo la parte activa de la mujer dentro del diálogo amatorio, sino, a la vez, y como contraparte dinámica, la impotencia del poeta atrapado irremediablemente, sin salida, por aquellos ojos que lo han hechizado.

En los versos segundo y tercero de esta estrofa encontramos, en primer lugar, una imagen cromática de gran eficacia ("una tarde amaranto"), la cual, por el tinte rojo vivo, supone la presencia, tácita e intensa, de una tizianesca puesta de sol; y en segundo lugar, una imagen musical de gran sonoridad, que surge de la secuencia amaranto - canto - cantos, y cuya resonancia orquestal se debe a la particular corporeidad sonora de la palabra amaranto, en posición de cesura (¿no habrá incluso una velada sugerencia en la raíz misma de la palabra?), a la iteración de la palabra canto(s) que, a su vez, contiene una imagen musical en lo semántico, a una imagen léxica ("dije un canto") de gran sobriedad, y, finalmente, al brusco encabalgamiento sus / cantos.

En el cuarto verso, "las dos lenguas de sus senos" (los pezones) se nos muestran abrasadas, sedientas. En la ecuación senos = lenguas está implicita, además de la sed, toda la carga de la sensualidad. Aquí la imagen está emparentada con los besos del verso 3: las puntas de los senos también están sedientas de besos. Por otra parte, esos senos hablan: la legitimidad semántica de la imagen se funda también en el hecho de que los senos ya no son senos, sino lenguas.

Las dos estrofas que siguen presentan un tono completamente distinto. Ya no se trata de un canto de amor con leve fondo de tristeza, sino de la propia tristeza, que se transfiere sobre la mujer, y de la gran ternura y compasión que el poeta - apagada, ahora, la sed de la pasión-siente por ella.

Adecuándose al nuevo ambiente anímico, la melodía formal adquiere un ritmo más lento; el tono musical tiende a apagarse; las pausas, no siempre representadas por la puntuación, se hacen más frecuentes y prolongadas, como para marcar la subterránea angustia del poeta, hasta el sincopato final del último verso, quebrado en cuatro grupos fónicos, como un llanto:

Pobre trigueña aquélla; pobres sus armas; pobres sus velas cremas que iban al tope en las salobres espumas de un marmuerto. Vencedora y vencida, se quedó pensativa, ojerosa y granate.

Yo me partí de aurora. Y desde aquel combate, de noche entran dos sierpes esclavas a mi vida.

Es pertinente, ante todo, la insistencia de la palabra clave de esa tristeza entremezclada de ternura. El calificativo interjectivo pobre está tan cargado, por sí solo, de afectividad y énfasis, que el poeta ni siquiera necesita agregarle el signo de exclamación correspondiente.

En seguida, el pronombre aquélla, con su vaga indeterminación, insiste en lo anónimo de esta mujer que ni siquiera tiene un nombre ficticio, ni tiene por qué tenerlo, puesto que pasa, como una "vela", por aquella noche del poeta (véase el verso siguiente). Este anonimato, por lo demás, acrecienta el sentimiento de compasión y ternura que hemos dejado apuntado. 
"Pobres sus armas": el poeta, desarmado, extiende su ternura a las. armas (encantos amorosos) con que ha sido vencido. En ello reside ya su íntima actitud de prescindencia, de trascendencia metafísica frente al amor carnal, que habrá de sublimarse, a través de distintas etapas, en poemas posteriores, hasta cantar el absurdo, el amor sexual asexuado (cf. el poema "Amor", ya citado, en Los heraldos negros).

"Pobres sus velas cremas": aparte de la imagen pura de las velas, a la que hemos aludido poco antes, y que representa sintética y plásticamente el tránsito fugaz de aquel amor del hic et nunc, nos interesa subrayar la excepcional elección cromática cremas. No se trata de las velas blancas (o negras) de siempre, sino de un color menos definido, menos puro, más flou, particularmente adecuado para una situación anímica como ésta ${ }^{9}$.

"En las salobres espumas de un marmuerto": la navegación de las velas (la historia fugaz de este amor) se produce sobre espumas (lo efímero), por demás salobres (amargas), y —ad abundantiam- sobre un marmuerto (la pasividad inerme e inerte del poeta, apuntada más arriba). Es notoria la eficacia estilística de la sutura en el término compuesto marmuerto, que anuncia ya la tendencia yuxtapositivo-sintético-combinatoria tan cara al Vallejo de los años siguientes ${ }^{10}$.

"Vencedora y vencida": en la primera parte del poema, era el poeta el vencido (asediado, desarmado, muerto) a pesar de la capitulación (formal) de la mujer; ahora, acabada la batalla de Eros, la mujer vencedora se halla, a la vez, vencida. Ahora capitula realmente: ya no más ante el hombre, por ella hechizado, ya no más con el sentimiento femenino de la victoria final; sino ante la vida misma, que no se concluye en la ilusión fugaz del acto amatorio; ante la realidad que se vuelve a presentar sombría y cotidiana con sus difuminadas interrogantes.

Frente a todo esto se queda perpleja, pensativa, ojerosa, como auscultando el futuro inminente, la separación inexorable que aparecerá en el verso que sigue. En la oposición pensativa / ojerosa ${ }^{11}$ se hallan los dos aspectos -el anímico y el carnal- de la derrota.

De todo aquel cuadro de amor con que se ha abierto el poema, ahora queda tan sólo el color granate. Pero esta vez se trata de un mero corolario físico, de un atributo corpóreo de la mujer: ha cesado la risueña y transparente metáfora inicial de los abriles grana.

Parte el poeta, en fin, como ya se ha presentido en el verso anterior, durante la aurora: y he aqui, una vez más, el color dominante de todo el poema, el rojo, difuminado en distintos matices (grana, amaranto; granate, aurora), como corresponde a una poesía de pasión. (Obsérvese, de paso, que esta delicada historia de amor empieza en una puesta de sol, en "una tarde amaranto", y termina en la "aurora". La economía estructural y el equilibrio del poema vallejiano, incluso en este aspecto formal, no podrían ser más clásicos) ${ }^{12}$.

* Sobre el cromatismo en Vallejo, cf. S. YURKievich, op. cit., p. 14.

1o Más tarde, esta tendencia se agudizará y llegará a tipos absurdos, por ejemplo, guillermosecundario. Para otros ejemplos, cf. S. Yunktevrch, op. cit., p. $3^{8}$.

I1 La imagen de las ojeras denota la influencia de Julio Herrera y Reissig, en quicn a menudo se inspira Vallejo. Cf. X. Arrr, op. cit., pp. 26 ss.

12 Sobre el clasicismo de Vallejo, en general, cf. X. Asrux, "Estimativa y universali- 
En este punto, ya habrá captado el lector los dos matices estilísticos (importantísimas elecciones) de la breve e inmejorable frase que comentamos: el pronombre me que acompaña y refuerza afectivamente al verbo partí (como si al poeta le costara alejarse), y el empleo excepcional (creador) del morfema de en el sintagma de aurora ${ }^{13}$. No partió el poeta a la aurora, al despuntar la aurora (aspecto puntual, incoativo de la acción), sino durante la aurora (aspecto durativo). La elección "durativa", en oposición a la "incoativa", es justamente el procedimiento estilístico que añade indeterminación, difuminación, sugestión poética a la partida, que ha de ser definitiva.

Este carácter definitivo, ya presentido, se concreta y precisa en la frase final ("Y desde aquel combate / de noche entran dos sierpes esclavas a mi vida") gracias al empleo de desde (puntual en su punto de partida, pero abierto, "apuntual", en su proyección hacia el futuro).

El término combate completa y sintetiza aquella terminología (y aquella atmósfera) que, al empezar nuestro examen, llamamos "bélica".

"De noche" hace pendant con "de aurora", aunque, en este caso, la fórmula lingüística es tradicional.

"Dos sierpes esclavas a mi vida": también aquí se presenta un problema semántico previo a toda consideración estilística: ¿Qué pueden significar esas sierpes? En el plano lírico, tenemos una reelaboración (esta vez más tensa) de la imagen anterior "las dos lenguas de sus senos", que, ahora bajo forma de sierpes, atormentan oníricamente al poeta: nocturnos fantasmas sexuales. La imagen no deja de ser poéticamente válida. Sin embargo, bajo la hermosa imagen lírica, para quien tenga en cuenta la concepción del amor sexual que se fue madurando en el curso de la vida (y de la obra) del poeta, aparece una importante motivación psicológica. Vallejo sentía ante el amor sexual ciertos conflictos espirituales que lo llevaron, a través de distintas etapas, a su sublimación en amor universal (cf., por ejemplo, "Traspié entre dos estrellas", en Poemas humanos, y "España, aparta de mí este cáliz", en el libro homónimo) En estos conflictos, posiblemente de origen religioso, como en el pesimismo del que constituyen una faceta, puede haber influido también alguna sacudida psicológica relacionada con sus primeras experiencias sexuales en los ambientes prostibularios del Perú ${ }^{14}$. El aspecto más evidente del conflicto es el sentimiento de culpa, de "pecado", frente al amor carnal (cf. el citado poema "Amor"). El complejo mismo, al sublimarse luego el amor sexual en amor universal, se dilata y extiende, más allá de la sensualidad, hasta alcanzar el terreno de la solidaridad humana para con los desconocidos. Entonces el poeta siente que lo que les falta a los demás se ha quedado "mal" en sus manos, "como cosa ajena" (cf. "Agape", en Los heraldos negros, y "El pan nuestro", ibid.). Las "dos sierpes" repre-

dad de César Vallejo", en la Antologia de César Vallejo, Ed. Claridad, Buenos Aires, 1942 , p. 8.

${ }_{13}$ El crítico que mejor ha destacado en Vallejo "el uso personalísimo, original, de los vocablos alusivos a la temporalidad", ha sido Xavier ABriL: cf. su Vallejo, op. cit, pp. $5^{6}$ ss.

${ }^{14}$ Sobre estos aspectos -trauma sexual, pesimismo, conflicto religioso-, cf. LuIs Mongutó, César Vallejo, New York, 1952, p. 55; X. Abril, opp. cit., p. 49; J. Larrea, op. cit., p. 53 . 
sentan, pues, el remordimiento por el amor-pecado que se le insinúa adentro, de noche, cuando los fantasmas suelen ser más activos. Su entrada en el alma del poeta no se limita a imágenes fugaces, meramente oníricas, sino que alcanza y traspasa su "vida" entera. En otras palabras: aquel episodio de amor tiene una repercusión anímica y moral mucho mayor de lo que a primera vista podría suponerse. Deja de ser mero episodio, para convertirse en uno de los tantos conflictos permanentes de Vallejo.

Nos queda por establecer el valor semántico-estilístico de la última imagen: esclavas (referida a sierpes). Creo que se trata, en lo semántico, de otra inversión (atrevida y acertada a la vez) de la imagen: no es que las sierpes del remordimiento sean esclavas del poeta, sino que el poeta es esclavo de ellas. No puede librarse de las sierpes, justamente porque pertenecen ya al tejido anímico de su complejo, son elementos obligados de su conflicto permanente. Claro está que la legitimidad semántica de la inversión es posible por la reversibilidad misma de la imagen: si el poeta es esclavo de las sierpes, éstas son esclavas de él; no pueden apartarse puesto que integran, obligadamente también, su realidad conflictual, su existencialidad humana. En una palabra: podrían salir de él sólo si él se liberara de ellas. Lo cual también puede representar una posibilidad clínica, objetiva, pero no una virtualidad subjetiva del hombre Vallejo, que no podía dejar de ser como era. En lo estilístico, la imagen de las "sierpes esclavas" contiene una fuerza expresiva cabalmente adecuada a aquella situación dinámica de ambivalente tensión, que hemos dejado apuntada. A su vez, la secuencia de las cinco eses, en posición privilegiada (absoluta), contribuye a reforzar, con su silbante corporeidad sonora, la imagen semántica que cierra plásticamente el poemá (a este propósito, recuérdese el endecasílabo de Racine: "Pour qui sont ces serpents qui sifflent sur ma tête").

Si ahora echamos una mirada de conjunto al cuadro, en seguida vemos que el marco ${ }^{15}$ está representado por dos ejes transversales que sostienen (y alimentan) el conjunto: el primero y el último verso:

Anoche unos abriles grana capitularon...

de noche entran dos sierpes esclavas a mi vida.

El primero, lleno de alegría, de alegría siniestra si se quiere; el último, lleno de "enfermedad", de sombra, de agonía. El sentimiento agónico es justamente el responsable anímico de aquella repartición melódica, quebrada como un sollozo, en los cuatro grupos de entonación, mortalmente sincopados, a los que nos hemos referido. Leámoslos de esta manera:

"de noche / entran dos sierpes // esclavas /// a mi vida".

Giovanni Meo Zilio

Firenze.

Is Sobre la noción de cuadro y de marco, en lo estilístico, cf. Giacomo Deyoro, Studi di stilistica, Firenze, 1950 , pp. 57 ss. 